\title{
Isotopic fractionation during soil uptake of atmospheric hydrogen
}

\author{
A. Rice ${ }^{1}$, A. Dayalu ${ }^{2, *}$, P. Quay ${ }^{3}$, and R. Gammon ${ }^{3}$ \\ ${ }^{1}$ Department of Physics, Portland State University, Portland, Oregon 97207-0751, USA \\ ${ }^{2}$ Harvard University Earth and Planetary Sciences, 20 Oxford Street, Cambridge Massachusetts, 02138, USA \\ ${ }^{3}$ School of Oceanography, P.O. Box 357940, University of Washington, Seattle, Washington 98195, USA \\ * formerly at: Department of Chemistry, University of Washington, USA
}

Received: 23 September 2010 - Published in Biogeosciences Discuss.: 1 November 2010

Revised: 18 February 2011 - Accepted: 1 March 2011 - Published: 23 March 2011

\begin{abstract}
Soil uptake of atmospheric hydrogen $\left(\mathrm{H}_{2}\right)$ and the associated hydrogen isotope effect were studied using soil chambers in a Western Washington second-growth coniferous forest. Chamber studies were conducted during both winter and summer seasons to account for large natural variability in soil moisture content (4-50\%) and temperature (6$\left.22^{\circ} \mathrm{C}\right) . \mathrm{H}_{2}$ deposition velocities were found to range from $0.01-0.06 \mathrm{~cm} \mathrm{~s}^{-1}$ with an average of $0.033 \pm 0.008 \mathrm{~cm} \mathrm{~s}^{-1}$ (95\% confidence interval). Consistent with prior studies, deposition velocities were correlated with soil moisture below $20 \%$ soil moisture content during the summer season. During winter, there was considerable variability observed in deposition velocity that was not closely related to soil moisture. The hydrogen kinetic isotope effect with $\mathrm{H}_{2}$ uptake was found to range from $-24 \%$ o to $-109 \%$. Aggregate analysis of experimental data results in an average KIE of $-57 \pm 5 \%$ o $(95 \%$ $\mathrm{CI})$. Some of the variability in KIE can be explained by larger isotope effects at lower $(<10 \%)$ and higher $(>30 \%)$ soil moisture contents. The measured KIE was also found to be correlated with deposition velocity, with smaller isotope effects occurring at higher deposition velocities. If correct, these findings will have an impact on the interpretation of atmospheric measurements and modeling of $\delta \mathrm{D}$ of $\mathrm{H}_{2}$.
\end{abstract}

\section{Introduction}

Molecular hydrogen $\left(\mathrm{H}_{2}\right)$ has a globally averaged mixing ratio of approximately $530 \mathrm{ppb}$ and is the second most abundant reduced trace gas after methane (Novelli, 1999). The study of $\mathrm{H}_{2}$ has warranted recent considerable attention due

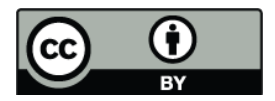

Correspondence to: A. Rice (arice@pdx.edu) to its potential as a future fuel source and its influences on the biogeochemical cycles of the atmospheric gases carbon monoxide $(\mathrm{CO})$, methane $\left(\mathrm{CH}_{4}\right)$, non-methane hydrocarbons (NMHC's) and water vapor $\left(\mathrm{H}_{2} \mathrm{O}\right)$ (Schultz et al., 2003; Tromp et al., 2003; Warwick et al., 2004).

The major sources of $\mathrm{H}_{2}$, accounting for $90 \%$ of the global burden, are photochemical oxidation of $\mathrm{CH}_{4}$ and NMHC's, fossil fuel combustion and biomass burning, whereas ocean degassing, volcanic emissions and production by legumes during $\mathrm{N}_{2}$ fixation make up the remaining $10 \%$ (see review by Ehhalt and Rohrer, 2009). Soil uptake of $\mathrm{H}_{2}$ is considered to account for $\sim 75 \%$ of the global $\mathrm{H}_{2}$ sink (Hauglustaine and Ehhalt, 2002; Price et al., 2007; Rahn et al., 2003; Sanderson et al., 2003) and the reason for the observed $\sim 3 \%$ higher $\mathrm{H}_{2}$ concentrations in the southern hemisphere compared to the Northern Hemisphere, which is atypical for an anthropogenically produced gas (Khalil and Rasmussen, 1989). Photochemical oxidation by the $\mathrm{OH}$ radical is responsible for the remaining $\sim 25 \%$ of the $\mathrm{H}_{2}$ sink (Novelli, 1999).

Despite a renewed research focus on the global $\mathrm{H}_{2}$ cycle, there are still substantial uncertainties in the $\mathrm{H}_{2}$ budget. Uncertainties in individual sources are commonly 25-50\% (Ehhalt and Rohrer, 2009). Furthermore, there is no consensus on the magnitude of the soil sink; recent work by Rhee et al. (2006) and Xiao et al. (2007) indicates that the soil sink could be responsible for more than $80 \%$ of $\mathrm{H}_{2}$ destruction. One of the primary reasons for this uncertainty in the sink, is the considerable variability that has been observed in the uptake rate of soils, much of which is not well characterized (Conrad and Seiler, 1985; Smith-Downey et al., 2008; Yonemura et al., 1999).

Measurements of the deuterium content of $\mathrm{H}_{2}$ provide one way to reduce the uncertainty in the $\mathrm{H}_{2}$ budget (Rice et al., 2010). Of particular potential, the difference between isotopic fractionations associated with $\mathrm{H}_{2}$ uptake by soils and

Published by Copernicus Publications on behalf of the European Geosciences Union. 
reaction with $\mathrm{OH}$ are large; the hydrogen kinetic isotope effect (KIE) in soil uptake is $k_{\mathrm{HD}} / k_{\mathrm{H}_{2}} \sim 0.94$ (Gerst and Quay, 2001 ) and in the reaction with $\mathrm{OH}$ is $k_{\mathrm{HD}} / k_{\mathrm{H}_{2}} \sim 0.70$ (Talukdar et al., 1996). Thus, HD can serve as a valuable tracer to distinguish between soil uptake and $\mathrm{OH}$ oxidation of $\mathrm{H}_{2}$ at the global scale. However, this approach relies on extensive knowledge of the HD content of atmospheric $\mathrm{H}_{2}$ and its spatial and temporal distribution. Additionally, source $\mathrm{HD} / \mathrm{H}_{2}$ signature ratios and isotopic fractionation from sinks must be fully characterized in order to provide additional constraint of the $\mathrm{H}_{2}$ budget (Price et al., 2007).

There have been few studies of the hydrogen KIE associated with soil uptake (Gerst and Quay, 2001; Rahn et al., 2002b) and none previous aimed at describing and understanding processes determining its variability. Here we present a series of field chamber experiments conducted over two seasons in a forest ecosystem to determine the magnitude of the KIE during HD uptake by soils and focus the work on characterizing variability across a wide range of soil moisture content.

\section{Experimental}

\subsection{Site description}

Soil uptake experiments were conducted in the Washington Park Arboretum in Seattle, Washington $\left(48^{\circ} \mathrm{N}, 122^{\circ} \mathrm{W}\right)$ during February, March and June 2006. The site is second growth coniferous forest with well-drained Indianola series soil formed in sandy glacial drift with minor amounts of volcanic ash. Indianola soils have neutral $\mathrm{pH}$, contain $0-15 \%$ rock fragments with fine, coarse and medium roots, and are usually moist except for the 60-75 days following summer solstice (Harrison, personal communication, 2006). The forest floor typically has a covering of leaf litter during the winter/spring experiments and grass patches during the summer experiments. The experimental sites were roughly cleared of duff before experimentation. Upland and lowland soils were chosen to encompass a natural range of soil moisture within a season.

\subsection{Sample collection}

The soil uptake experiments were conducted using a $215 \mathrm{~L}$ rigid static flux chamber with a $0.57 \mathrm{~m}^{2}$ footprint and an internal fan circulating the air inside. The chamber was placed over the soil and driven into the ground to an approximate depth of $1.5 \mathrm{~cm}$. Air samples from within the chamber were collected using pre-evacuated $500 \mathrm{~mL}$ glass flasks at 0,10 and $20 \mathrm{~min}$ after the start of the experiment. Flasks were allowed to equilibrate with the chamber air for 15 seconds. In total, 15 individual soil uptake experiments were performed over three days in wet and dry seasons. At the conclusion of each experiment, representative surface soil samples
( 50-100 g) were collected and double bagged in Ziploc bags for moisture analysis.

\subsection{Analysis}

All $\mathrm{H}_{2}$ concentrations were measured using a Trace Analytical Reduction Gas Analyzer RGA3, (Model E-001) gas chromatography system with a $\mathrm{N}_{2}$ carrier gas as described previously (Gerst and Quay, 2000). Alternating sample/standard injections of $20 \mathrm{~mL}$ aliquots were passed through a $5 \mathrm{~mL}$ sample loop and measured on the RGA. The detection limit is $5 \mathrm{ppb}$. The software program Peak Simple calculates the peak heights and $\mathrm{H}_{2}$ concentrations are determined against the standards of known concentration. The precision of the measurement is $+1.4 \%$, determined by analyzing replicates of four manometrically prepared $\mathrm{H}_{2}$ standards which ranged between 100 and $548 \mathrm{ppb}$.

To separate the $\mathrm{H}_{2}$ for isotopic analysis we used a small volume technique previously described in detail (Rahn et al., 2002a; Rhee et al., 2004; Rice et al., 2010). Briefly, the air sample is allowed to transfer to a cryogenic trap at $40 \mathrm{~K}$, which freezes out the major atmospheric gases but allows $\mathrm{H}_{2}$ to remain in the gaseous state. Helium carrier gas is used to transfer the $\mathrm{H}_{2}$ to a U-tube packed with molecular sieve immersed in liquid nitrogen, which has been super cooled to $63 \mathrm{~K}$ by lowering the headspace pressure. The molecular sieve trap is then transferred to a continuous-flow isotope ratio mass spectrometer for isotopic analysis using a simple inlet system. An Agilent 6890GC regulating a Restek MXT-5A PLOT column $\left(15 \mathrm{~m} \times 0.53 \mathrm{~mm}\right.$, isothermal at $30^{\circ} \mathrm{C}, 1.5 \mathrm{bar}$ helium carrier) cryofocuses, separates, and admits the $\mathrm{H}_{2}$ to a ThermoFinnigan model 253 isotope ratio mass spectrometer through an open split interface to measure the $\mathrm{D} / \mathrm{H}$. The overall precision of the $\delta \mathrm{D}$ measurement is $5 \%$, where $\delta \mathrm{D}=\left[(\mathrm{D} / \mathrm{H})_{\text {sample }} /(\mathrm{D} / \mathrm{H})_{\mathrm{VSMOW}}-1\right] 1000$ and the standard is Vienna Standard Mean Ocean Water (VSMOW) (Hagemann et al., 1970; Gonfiantini et al., 1995).

To measure soil moisture, soil samples of $20-40 \mathrm{~g}$ are weighed and then baked at $110^{\circ} \mathrm{C}$ for one hour. The dry mass is recorded and the sample is replaced in the oven for another $30 \mathrm{~min}$ and reweighed repeatedly until two consecutive weightings agree within $0.01 \mathrm{~g}$. Percent moisture saturation equals $100\left(m_{\text {wet }}-m_{\text {dry }}\right) / m_{\text {wet }}$, where $m_{\text {wet }}$ is the initial wet soil mass and $m_{\text {dry }}$ is the final dry soil mass.

\section{Results and discussion}

\section{1 $\quad \mathrm{H}_{2}$ uptake rates}

During the 15 experiments the $\mathrm{H}_{2}$ concentration within the chamber decreased by a range of 58 to $95 \%$ over the $20 \mathrm{~min}$ chamber deployments (Fig. 1a). The rate of change of $\mathrm{H}_{2}$ 


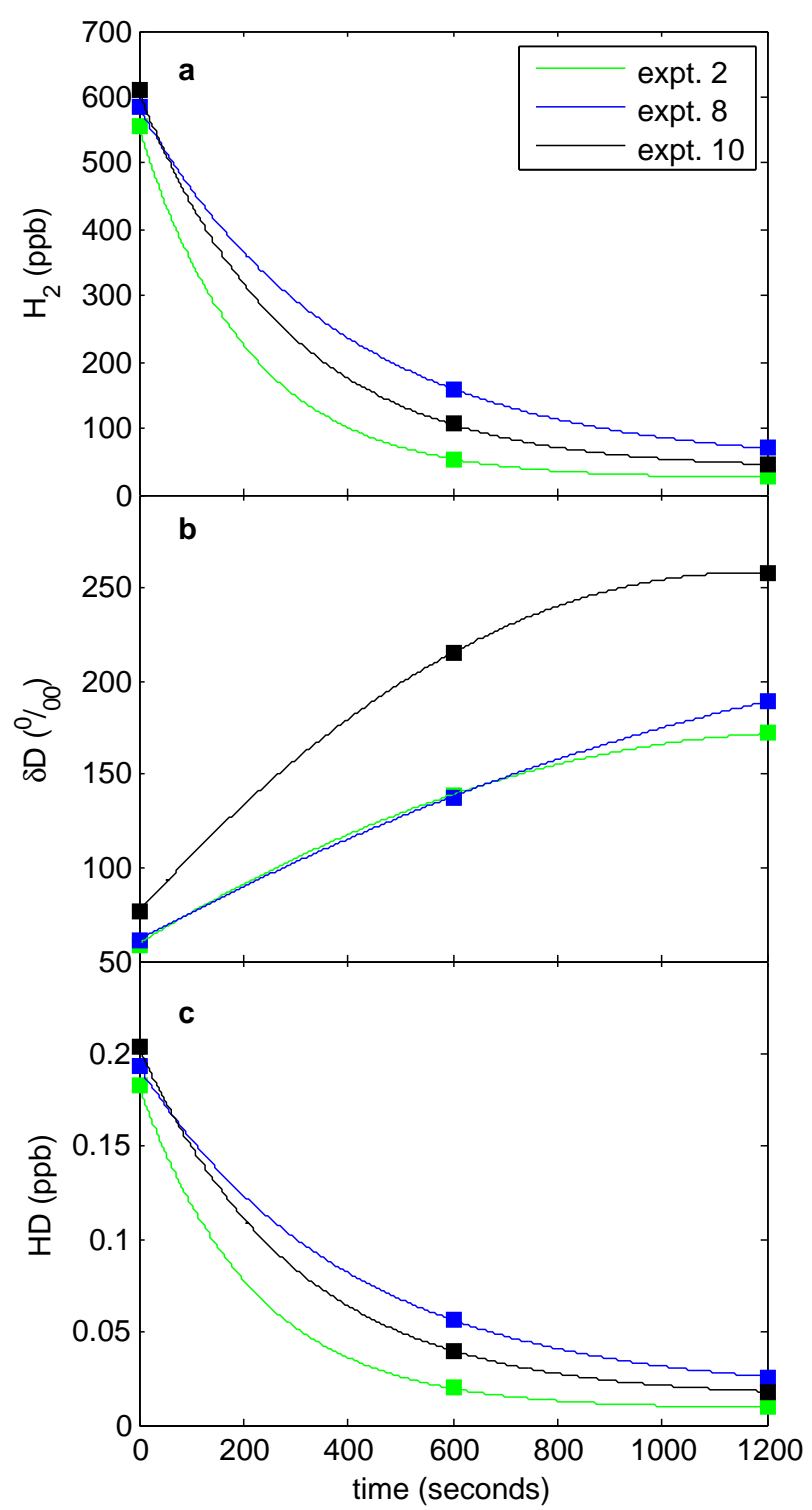

Fig. 1. Observed chamber concentrations of $\mathrm{H}_{2}$ (a), $\delta \mathrm{D}(\mathbf{b})$, and HD (c) during three representative experiments: experiment 2 (green squares), experiment 8 (blue squares), experiment 10 (black squares). Fits shown are based on Eqs. (2) and (4) for $\mathrm{H}_{2}$ and HD from which decay constants were calculated. Measurement uncertainties are smaller than individual symbols.

inside the chamber can be modeled by the balance between production and consumption:

$\frac{d \mathrm{H}_{2}}{d t}=P_{\mathrm{H}_{2}}-k_{\mathrm{H}_{2}} \mathrm{H}_{2}$

where production of $\mathrm{H}_{2}$ in the subsurface $\left(P_{\mathrm{H}_{2}}\right)$ is zero-order in $\mathrm{H}_{2}$ and the consumption $\left(k_{\mathrm{H}_{2}}\right)$ is first order in $\mathrm{H}_{2}$. We note the consumption term is first order in $\mathrm{H}_{2}$ regardless if consumption is limited by diffusion (Fick's first law) or enzyme kinetics (Schmitt et al., 2009). Though in all experiments consumption outweighed production, evidence for a subsurface $\mathrm{H}_{2}$ source is demonstrated by the decay of $\mathrm{H}_{2}$ to non-zero asymptote (Fig. 1a) and previously measured belowground non-zero $\mathrm{H}_{2}$ concentrations (Conrad and Seiler, 1985; Smith-Downey et al., 2008; Yonemura et al., 2000). The solution to Eq. (1) is of the form:

$\mathrm{H}_{2}=\mathrm{H}_{2_{\mathrm{i}}} \exp \left(-k_{\mathrm{H}_{2}} t\right)+\mathrm{H}_{2_{\mathrm{e}}}\left(1-\exp \left(-k_{\mathrm{H}_{2}} t\right)\right)$

where $k_{\mathrm{H}_{2}}$ is the first order loss coefficient and $\mathrm{H}_{2}$ is the mixing ratio at time $t\left(\mathrm{H}_{2}\right)$, initially $\left(\mathrm{H}_{2_{\mathrm{i}}}\right)$, and at equilibrium $\left(\mathrm{H}_{2 \mathrm{e}}\right)$. In this work we report net uptake as a deposition velocity $\left(\mathrm{cm} \mathrm{s}^{-1}\right) v_{\mathrm{d}}=k_{\mathrm{H}_{2}} \times H$ where $H$ is the effective chamber height, equal to the ratio of the volume to surface area of the chamber $(12 \pm 1 \mathrm{~cm})$ (Conrad and Seiler, 1985).

This approach was applied by iteratively fitting our experimental $\mathrm{H}_{2}$ data from each experiment until convergence was reached $\left(r^{2}>0.99\right)$ (Fig. 1a). Resulting deposition velocities for the 15 field chamber experiments are shown in Table 1. Equilibrium $\mathrm{H}_{2}$ values $\left(\mathrm{H}_{2 \mathrm{e}}\right)$ were determined to vary widely from 0 to $118 \mathrm{ppb}$ and were unrelated to deposition velocity. Results from one chamber experiment (experiment 7) was also excluded from our pooled analyses (see below) as it contains a sample that was lost prior to analysis; the reported uptake rate for this experiment is based on a strict first order loss rate. Including uptake rates from experiment 7 in pooled uptake rates does not change the conclusions, though it may bias the quantitative result.

Measured deposition velocities ranged from 0.012 to $0.058 \mathrm{~cm} \mathrm{~s}^{-1}$ with a mean of $0.033 \pm 0.008 \mathrm{~cm} \mathrm{~s}^{-1}(95 \%$ confidence interval) (Table 1). This range of deposition velocity is wider than but overlaps with previous experimental determinations of deposition velocity at this site during summer which ranged from 0.03 to $0.06 \mathrm{~cm} \mathrm{~s}^{-1}$ (Gerst and Quay, 2001). Additional comparison can be made to a number of studies of $\mathrm{H}_{2}$ uptake rate including those in: desert and grassland (0.01 to $0.14 \mathrm{~cm} \mathrm{~s}^{-1}$, Conrad and Seiler, 1985); agricultural and forested sites in Japan $\left(0.01\right.$ to $0.09 \mathrm{~cm} \mathrm{~s}^{-1}$, Yonemura et al., 1999, 2000); forested sites in Alaska (0.04 to $0.07 \mathrm{~cm} \mathrm{~s}^{-1}$, Rahn et al., 2002b); forest, desert, and marsh sites in southern California $\left(0.02\right.$ to $0.10 \mathrm{~cm} \mathrm{~s}^{-1}$, SmithDowney et al., 2008); boreal forests in Finland (0.04 to $0.07 \mathrm{~cm} \mathrm{~s}^{-1}$, Lallo et al., 2008), and agricultural fields in Germany (0.009 to $0.08 \mathrm{~cm} \mathrm{~s}^{-1}$, Schmitt et al., 2009).

Over two seasons, soil moisture content ranged from 5$50 \%$, with lower soil moistures during summer months (4$20 \%$ ). At lower soil moisture contents during the summer experiments, we found a significant positive correlation between deposition velocity and soil moisture (Fig. 2a, $r^{2}=0.61, p<0.05$. This finding is consistent with previous field experiments and laboratory studies of $\mathrm{H}_{2}$ uptake rates which indicate lower microbial activity at low soil moisture contents (Conrad and Seiler, 1985; Smith-Downey et al., 2006). Winter experiments had considerably higher variability in deposition velocity that was not statistically linked to 


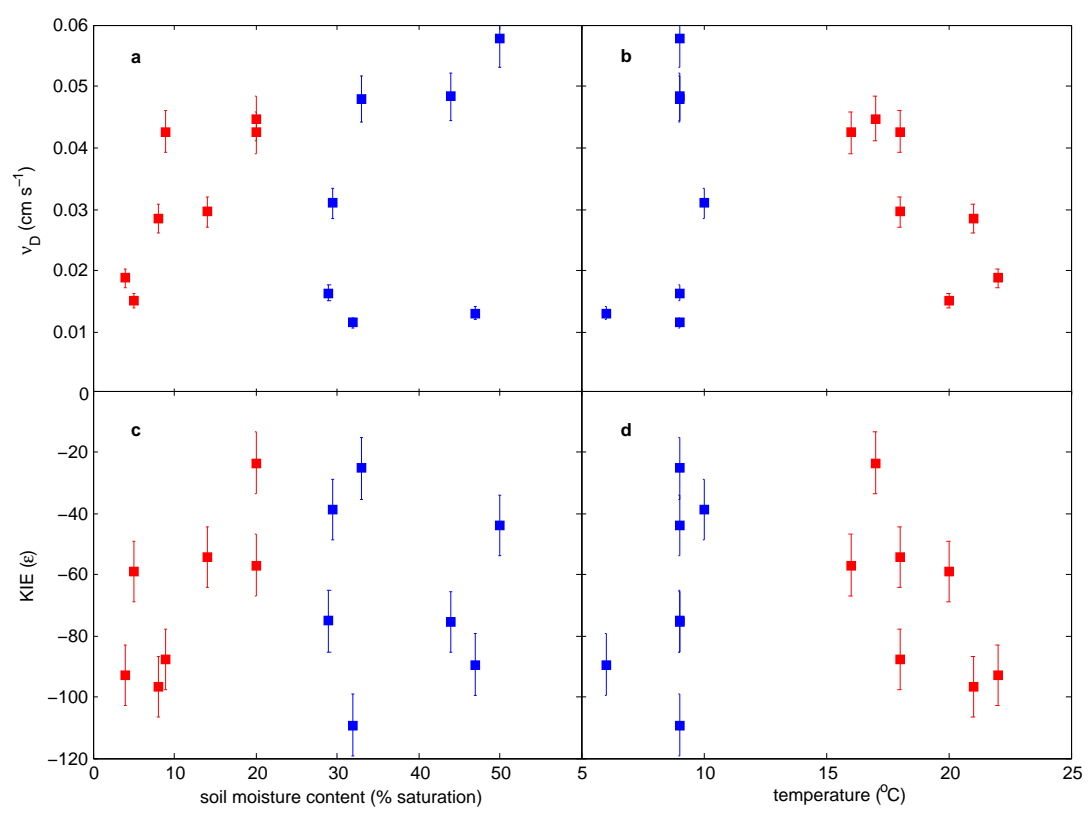

Fig. 2. Deposition velocity $(\mathbf{a}, \mathbf{b})$ and kinetic isotope effect $(\mathbf{c}, \mathbf{d})$ plotted versus soil moisture $(\mathbf{a}, \mathbf{c})$ and temperature $(\mathbf{b}, \mathbf{d})$ during the chamber experiments during the winter season (blue squares) and summer season (red squares).

Table 1. Select data from field experiments including experiment number, soil temperature, soil moisture content, deposition velocity $\left(v_{\mathrm{d}}\right)$, and the calculated kinetic isotope effect $(\varepsilon)$.

\begin{tabular}{llrrcl}
\hline Exp\# & Date and Time & $\begin{array}{r}T \\
\left({ }^{\circ} \mathrm{C}\right)\end{array}$ & $\begin{array}{c}(\%) \\
\left(\mathrm{cm} \mathrm{s}^{-1}\right)\end{array}$ & $\begin{array}{l}v_{\mathrm{a}}^{\mathrm{a}}(\varepsilon)^{\mathrm{b}} \\
(\%)\end{array}$ \\
\hline 1 & $2 / 16 / 200617: 25$ & 6 & 47 & 0.013 & -90 \\
2 & $3 / 29 / 200611: 10$ & 9 & 50 & 0.058 & -44 \\
3 & $3 / 29 / 200611: 30$ & 9 & 44 & 0.048 & -76 \\
4 & $3 / 29 / 200612: 00$ & 9 & 29 & 0.016 & -75 \\
5 & $3 / 29 / 200612: 30$ & 9 & 32 & 0.012 & -109 \\
6 & $3 / 29 / 200612: 55$ & 9 & 33 & 0.048 & -25 \\
7 & $3 / 29 / 200613: 20$ & 9 & 32 & 0.022 & -50 \\
8 & $3 / 29 / 200613: 50$ & 10 & 30 & 0.031 & -39 \\
9 & $6 / 28 / 200610: 50$ & 20 & 5 & 0.015 & -59 \\
10 & $6 / 28 / 200612: 00$ & 16 & 20 & 0.043 & -57 \\
11 & $6 / 28 / 200612: 45$ & 17 & 20 & 0.045 & -24 \\
12 & $6 / 28 / 200613: 20$ & 18 & 9 & 0.043 & -88 \\
13 & $6 / 28 / 200613: 45$ & 18 & 14 & 0.030 & -54 \\
14 & $6 / 28 / 200614: 15$ & 22 & 4 & 0.019 & -93 \\
15 & $6 / 28 / 200614: 50$ & 21 & 8 & 0.028 & -97 \\
\hline
\end{tabular}

${ }^{a}$ Deposition velocities $\left(v_{\mathrm{d}}\right)$ were calculated using Eq. (2) and have an error of $\sim 8 \%$ primarily as a result of the error in effective chamber height, $H$.

${ }^{b}$ Kinetic isotope effects $(\varepsilon)$ were calculated using Eqs. (2) and (4) which permit $\mathrm{H}_{2}$ and $\mathrm{HD}$ to decay to non-zero asymptotic concentrations. Uncertainty is $\sim 10 \%$ o determined by bootstrapping uncertainties in $\mathrm{H}_{2}$ and $\delta \mathrm{D}$ in the calculation of decay constants. soil moisture content (Fig. 2a, $r^{2}=0.20, p>0.1$ ). Previous work has shown a decrease in deposition velocities associated with higher soil moisture contents $>40 \%$ due to the decrease in $\mathrm{H}_{2}$ diffusivity at higher saturations (Lallo et al., 2008; Smith-Downey et al., 2006; Yonemura et al., 1999).

Soil temperatures, measured at $5 \mathrm{~cm}$ depth, ranged $6-22^{\circ} \mathrm{C}$ in the 15 experiments. Over this temperature range, there was no correlation found between deposition velocity and soil temperature (Fig. $2 \mathrm{~b}, r^{2}=0.01$ ). However, measurements made during summer indicate an inverse dependence of deposition velocity on temperature over the range 16$22{ }^{\circ} \mathrm{C}$ (Fig. $2 \mathrm{~b}, r^{2}=0.67, p<0.05$ ). At first consideration, this finding appears at odds with previous laboratory studies which show an increase in deposition velocity with temperature (e.g., Liebel and Seiler, 1976; Smith-Downey et al., 2006) and with field studies that show little dependence on uptake rate above freezing temperatures (Conrad and Seiler, 1985; Lallo et al., 2008; Yonemura et al., 1999). Additionally, the inverse correlation observed here is counterintuitive as both diffusion and microbial enzymatic activity are more rapid at higher temperatures (over this temperature range). Our results can be reconciled with previous work by the strong inverse dependence of soil temperature with soil moisture found in these field experiments $\left(r^{2}=0.87\right)$. This is due to the coincidence of the wet-cool season and the warm-dry season climatology of the Pacific Northwest United States. Finally, other potential factors controlling $\mathrm{H}_{2}$ deposition velocities include soil porosity and microbial populations, variables which may help explain additional variability observed in these results (Conrad, 1996; Schmitt et al., 2009). 


\subsection{Kinetic isotope effect}

The $\delta \mathrm{D}$ of $\mathrm{H}_{2}$ within the chamber increased by a range of 20 to $200 \%$ over the 20 min chamber deployment during the 15 experiments (Fig. 1b). In all experiments, the $\delta \mathrm{D}$ increase was associated with a decrease in the $\mathrm{H}_{2}$ concentration, indicating that the loss rate of HD was slower than the loss rate of $\mathrm{H}_{2}$ in the chamber. The ratio of these loss rates defines the KIE for the process $\left(\alpha=k_{\mathrm{HD}} / k_{\mathrm{H}_{2}}\right)$. In a closed system, the Rayleigh distillation relationship describes the change in $\mathrm{D} / \mathrm{H}$ ratio during consumption of $\mathrm{H}_{2}$ :

$$
\frac{(\mathrm{D} / \mathrm{H})}{(\mathrm{D} / \mathrm{H})_{\mathrm{i}}}=\left(\frac{\mathrm{H}_{2}}{\mathrm{H}_{2_{\mathrm{i}}}}\right)^{\alpha-1}
$$

where the $\mathrm{D} / \mathrm{H}$ of $\mathrm{H}_{2}$ at time $t$ is a function of the initial ratio $(\mathrm{D} / \mathrm{H})_{\mathrm{i}}$, the $\mathrm{H}_{2}$ concentration at initial and time $t$, and $\alpha$. The KIE can be determined by linear regression of a log-log plot. This approach has been used in two previous studies of the KIE associated with soil uptake of $\mathrm{H}_{2}$ (Gerst and Quay, 2001; Rahn et al., 2002b).

Acknowledging the non-zero asymptotic behavior of $\mathrm{H}_{2}$ and HD in the chamber here, it is more accurate to model HD in the approach of Eq. (2):

$\mathrm{HD}=\mathrm{HD}_{\mathrm{i}} \exp \left(-k_{\mathrm{HD}} t\right)+\mathrm{HD}_{\mathrm{e}}\left(1-\exp \left(-k_{\mathrm{HD}} t\right)\right)$

which accounts for nonlinearity in a log-log Rayleigh plot (Eq. 3) due to the small $\mathrm{H}_{2}$ and $\mathrm{HD}$ belowground source (Eq. 1). An iterative method is applied to fit HD concentrations in the chamber (Fig. 1c) and results in a first order loss coefficient for $\mathrm{k}_{\mathrm{HD}}$ for each experiment and an equilibrium value for $\mathrm{HD}$ ( $\mathrm{HD}_{\mathrm{e}}$ which ranged from 0 to $0.03 \mathrm{ppb}$ ). The KIE associated with soil uptake is obtained from fitting $\mathrm{H}_{2}$ and $\mathrm{HD}$ data with Eqs. (2) and (4), respectively. Results of this analysis are shown for each field chamber experiment in Table 1.

Based on this approach, the KIE associated with soil uptake is found to range from $\alpha=0.891$ to 0.977 with an average of $\alpha=0.934 \pm 0.03(1 \sigma)$. This corresponds to an average fractionation factor, $\varepsilon=-66 \pm 30 \%$, where $\varepsilon=(\alpha-$ 1)(1000). Additionally, we use normalized aggregate data for an estimation of the average observed KIE, combining Eqs. (2) and (4):

$\ln \left(\frac{\mathrm{HD}-\mathrm{HD}_{\mathrm{e}}}{\mathrm{HD}_{\mathrm{i}}-\mathrm{HD}_{\mathrm{e}}}\right)=\alpha \ln \left(\frac{\mathrm{H}_{2}-\mathrm{H}_{2_{\mathrm{e}}}}{\mathrm{H}_{2_{\mathrm{i}}}-\mathrm{H}_{2_{\mathrm{e}}}}\right)$

Robust least squares regression (bisquare) for data from the 14 experiments (Fig. 3), considering uncertainty in both $\mathrm{H}_{2}$ and HD variables, results in an average $\alpha=0.943 \pm 0.005$, which corresponds to an $\varepsilon=-57 \pm 5 \%$ o $\left(r^{2}=0.9994,95 \%\right.$ $\mathrm{CI})$. We assume this approach for estimating the average KIE is most accurate since it is less susceptible to outliers. This mean result is indistinguishable from a previous study at this same experimental site during summer $(-57 \pm 24 \%$ o (Gerst and Quay, 2001) and from a forested site in Alaska $(-60 \pm 10 \%$ o) (Rahn et al., 2002b).

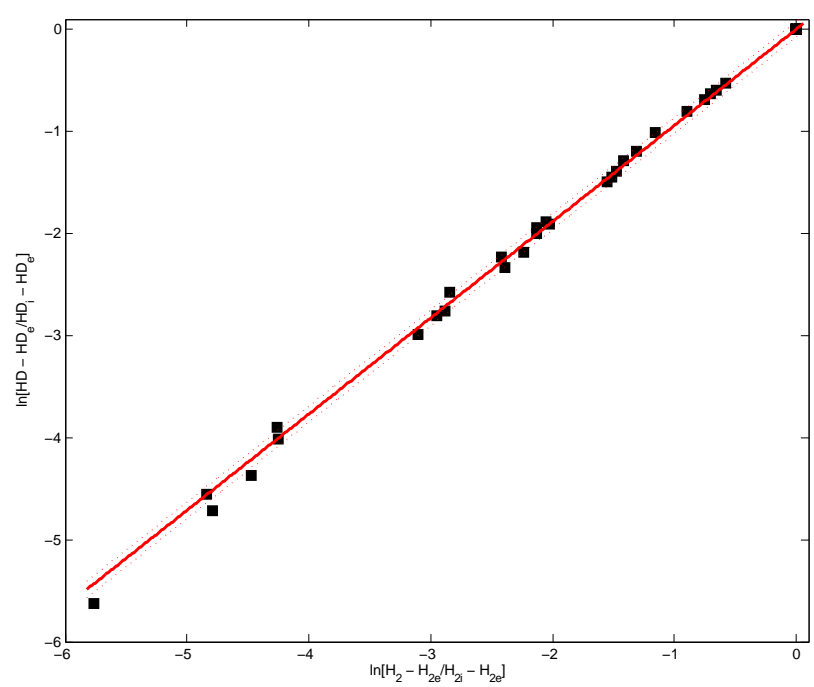

Fig. 3. Aggregate data analysis for the calculation of the mean kinetic isotope effect based on the equilibrium model from all experiments (Eq. 5). Least squares regression of these data, considering errors in both $\mathrm{H}_{2}$ and $\mathrm{HD}$ variables, results in a value of $\varepsilon=-57 \pm 5 \%$ o $\left(r^{2}=0.9994,95 \% \mathrm{CI}\right)$.

There is considerable evidence of a dependence of KIE on soil moisture content (Fig. 2c). In particular, during dry season experiments (summer) where soil moisture content was $<20 \%$ we observe a significant correlation between soil moisture and $\operatorname{KIE}\left(r^{2}=0.55, p<0.05\right.$, two-sided t-test $)$. Over this interval (0-20\%), $\varepsilon$ is found to vary from $-97 \%$ to $-24 \%$ o with larger KIEs found at lower soil moisture content. Results also indicate that the KIE is smaller at intermediate soil moisture contents 10-30\% when compared against aggregate lower and higher soil moisture (Fig. 2c, mean difference $26 \%, p<0.1$, two sided t-test). This interval is the same where $\mathrm{H}_{2}$ deposition velocities are typically higher (Fig. 2a).

As with deposition velocity, no significant correlation was found between soil temperature and KIE (Fig. 2d, $r^{2}=0.01$ ) over the entire range of experimental conditions $\left(6-22^{\circ} \mathrm{C}\right)$. However, summer experiments $\left(16-22^{\circ} \mathrm{C}\right)$ did exhibit an inverse relationship between KIE and temperature (Fig. 2d, $r^{2}=0.47, p<0.1$. Like deposition velocity, we assume this association is subject to the strong correlation between soil moisture and temperature in these field experiments. Conversely, as theory would predict a smaller enzymatic KIE at higher temperatures during $\mathrm{H}_{2}$ consumption, we cannot rule out the role of temperature in this result. However, were this a strong driver of KIE variability we would expect to see this effect in winter experiments at lower temperatures $\left(6-10^{\circ} \mathrm{C}\right)$ as non-linear effects with temperature are difficult to account for.

Finally, there is a significant correlation between deposition velocity and KIE, with a larger isotope effect observed 


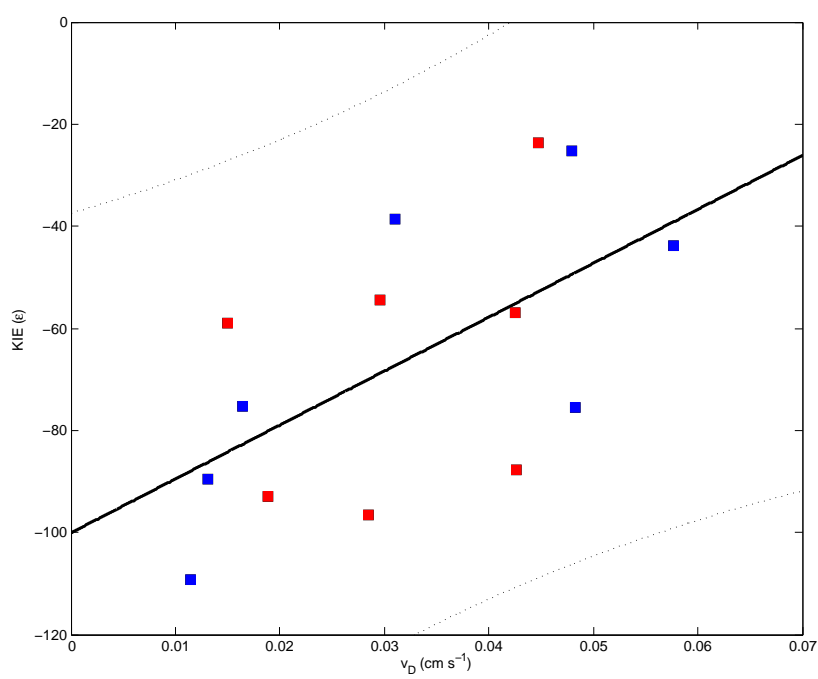

Fig. 4. The correlation of deposition velocity and kinetic isotope effect for chamber experiments conducted during winter (blue squares) and summer (red squares) seasons. Linear fit shown (solid line) with $95 \%$ confidence interval (dotted line) is indicative of a relationship between the two variables $\left(r^{2}=0.27, p<0.05\right)$.

at lower deposition velocity (Fig. $4, r^{2}=0.27, p<0.05$ ). Over the range of measured deposition velocity $(0.012$ to $0.058 \mathrm{~cm} \mathrm{~s}^{-1}$ ) we find a $\sim 10 \%$ decrease in the magnitude of $\varepsilon$ for an increase of $0.01 \mathrm{~cm} \mathrm{~s}^{-1}$. If correct, these findings are significant towards quantifying variability in the KIE associated with soil uptake of $\mathrm{H}_{2}$. Since the uptake rate of $\mathrm{H}_{2}$ in these experiments reflects both diffusion and consumption, the net KIE is considered to be a function of both processes, $\alpha_{\text {net }}=\left(\alpha_{\text {diffusion }} \alpha_{\text {consumption }}\right)^{1 / 2}$ (Bender, 1990; Snover and Quay, 2000). The KIE of $\mathrm{H}_{2}$ diffusing in air depends marginally on soil porosity (Mason and Malinauskas, 1983). In pore sizes $2-50 \mathrm{~nm}$ Knudsen diffusion will dominate; the KIE for Knudsen flow is estimated by the ratio of the square root of inverse mass, $\varepsilon=-184 \%$. In pore sizes $>50 \mathrm{~nm}$, molecular diffusion will dominate; the KIE for molecular diffusion is estimated by the ratio of the square root of the reduced masses of $\mathrm{H}_{2}$ and $\mathrm{HD}$ in air, $\varepsilon=-170 \%$. Though the magnitude of the microbial KIE is unknown, we infer that it must be relatively small so that $\alpha_{\text {net }}$ falls between the limits of $\alpha_{\text {diffusion }}$ and $\alpha_{\text {consumption, }}$, consistent with observations here and previously. It is plausible that in the midmoisture regime (10-30\%), where $\mathrm{H}_{2}$ uptake rate is typically greatest due to a low moisture barrier and higher microbial activity, consumption is not diffusion-limited and $\alpha_{\text {net }}$ approaches the bacterial limit $\left(\alpha_{\text {consumption }}\right)$.

\section{Conclusions}

The uptake of $\mathrm{H}_{2}$ by soils was found to have an average KIE of $\varepsilon=-57 \pm 5 \%$ in close agreement with previous studies. However, over a wide range of temperature, soil moisture content, and deposition velocity, the KIE was found to have considerable variability, $-24 \%$ o to $-109 \%$. Some of this variability may be associated with soil moisture content, as a smaller KIE was found at intermediate soil moisture contents (10-30\%). Additionally, during summer experiments the KIE was found to be related to soil moisture content and to temperature. A correlation between deposition velocity and KIE was also found, with the observed isotope effect larger at low deposition velocity. Finally, since soil moisture, temperature, and deposition velocity only relate to a fraction of the observed variability in the KIE, additional variability may be controlled by different reaction kinetics of microbial populations (Conrad, 1996).

Additional field studies of the KIE during $\mathrm{H}_{2}$ soil uptake will be needed to confirm this result. Laboratory studies to measure the KIE during bacterial $\mathrm{H}_{2}$ oxidation would also be particularly useful for interpreting field data and distinguishing between physical and biological processes. Laboratory studies of diffusional effects of atmospheric $\mathrm{H}_{2}$ in sterilized soils might also help to quantify the effect of transport on KIEs observed in the field. In any case, if correct, KIE dependencies on soil moisture and uptake rate, in particular, will affect both seasonal and meridional trends in the $\delta \mathrm{D}$ of atmospheric $\mathrm{H}_{2}$ (Rice et al., 2010), especially in situations where high rates of $\mathrm{H}_{2}$ soil uptake affect atmospheric $\mathrm{H}_{2}$ concentrations (e.g., forest air). As the $\delta \mathrm{D}$ of $\mathrm{H}_{2}$ is incorporated into models, including these KIE dependencies in soil uptake will be critical to correctly modeling the $\delta \mathrm{D}$ of atmospheric $\mathrm{H}_{2}$ and using it as an additional constraint on the global $\mathrm{H}_{2}$ budget (Price et al., 2007).

Acknowledgements. We thank J. Stutsman, C. Peacock, I. Jen-La Plante, and M. Haught for their valuable assistance in the lab and the field. R. Harrison of the UW College of Forest Resources provided information on the soil series in this study. We also thank T. Rahn for helpful comments on an early draft of the manuscript. We gratefully acknowledge support from the Mary Gates Endowment for student research, NASA Space Grant Consortium, and the Univ. of Washington Astrobiology program. Funding for this work was provided by a NSF research grant (ATM 0091878) and a Royalty Research Grant. This work was also partially funded by the Joint Institute for the Study of the Atmosphere and Ocean (JISAO) under NOAA Cooperative agreement NA17RJ1232, Contribution 1420.

Edited by: A. Shemesh

\section{References}

Bender, M.: The $\delta^{18} \mathrm{O}$ of dissolved $\mathrm{O}_{2}$ in seawater: A unique tracer of circulation and respiration in the deep sea, J. Geophys. Res., 95, 22243-22252, 1990.

Conrad, R.: Soil microorganisms as controllers of atmospheric trace gases $\left(\mathrm{H}_{2}, \mathrm{CO}, \mathrm{CH}_{4}, \mathrm{~N}_{2} \mathrm{O}\right.$, and $\left.\mathrm{NO}\right)$, Microbiol. Rev., 60, 609640, 1996.

Conrad, R. and Seiler, W.: Influence of temperature, moisture and organic carbon on the flux of $\mathrm{H}_{2}$ and $\mathrm{CO}$ between the soil and at- 
mosphere: Field studies in subtropical regions, J. Geophys. Res., 90, 5699-5709, 1985.

Ehhalt, D. and Rohrer, F.: The tropospheric cycle of $\mathrm{H}_{2}$ : A crtical review, Tellus, 61N, 500-535, 2009.

Gerst, S. and Quay, P.: The deuterium content of atmospheric molecular hydrogen: Method and initial measurements, J. Geophys. Res., 105, 26433-26445, 2000.

Gerst, S. and Quay, P.: Deuterium component of the global molecular hydrogen cycle, J. Geophys. Res., 106, 5021-5031, 2001.

Gonfiantini, R., Stichler, W., and Rozanski, K.: Standards and intercomparison materials distributed by the international atomic energy agency for stable isotope measurements, in reference and intercomparison materials for light elements, IAEA, Vienna, Austria, TECDOC-825, 13-29, 1995.

Hagemann, R., Nief, G., and Roth, E.: Absolute isotopic scale for deuterium analysis of natural waters, Absolute $\mathrm{D} / \mathrm{H}$ ratio for SMOW, Tellus, 22, 712-715, 1970.

Hauglustaine, D. A. and Ehhalt, D. H.: A three-dimensional model of molecular hydrogen in the troposphere, J. Geophys. Res., 107(D17), 4330, doi:10.1029/2001JD001156, 2002.

Khalil, M. A. K. and Rasmussen, R. A.: Seasonal cycles of hydrogen and carbon monoxide in the polar regions: Opposite phase change relationships, Antarct. J. US., 23, 238-239, 1989.

Lallo, M., Aalto, T., Laurila, T., and Hatakka, J.: Seasonal variations in hydrogen deposition to boreal forest soil in southern finland, Geophys. Res. Lett., 35, L04402, doi:10.1029/2007g1032357, 2008.

Liebl, K. H. and Seiler, W.: $\mathrm{CO}$ and $\mathrm{H}_{2}$ Destruction at the Soil Surface, in: Production and Utilisation of Gases, edietd by: Schlegel, H. G., Gottschalk, G., and Pfenning, N., E. Goltze KG, Göttingen, Germany, 215-229, 1976.

Mason, E. A. and Malinauskas, A. P.: Gas transport in porous media: The dusty-gas model, Elsevier, New York, 1983.

Novelli, P. C., Lang, P. M., Masarie, K. A., Hurst, D. F., Meyers, R., and Elkins, J. W.: Molecular hydrogen in the troposphere: Global distribution and budget, J. Geophys. Res., 104, 3042730444, 1999.

Price, H., Jaeglé, L., Rice, A., Quay, P., Novelli, P. C., and Gammon, R.: Global budget of molecular hydrogen and its deuterium content: Constraints from ground stations, cruise, and aircraft observations, J. Geophys. Res., 112, D22108, doi:10.1029/2006JD008152, 2007.

Rahn, T., Kitchen, N., and Eiler, J.: D/H ratios of atmospheric $\mathrm{H}_{2}$ in urban air: Results using new methods for analysis of nanomolar $\mathrm{H}_{2}$ samples, Geochim. Cosmochim. Acta, 66, 2475-2481, 2002a.

Rahn, T., Eiler, J. M., Kitchen, N., Fessenden, J. E., and Randerson, J. T.: Concentration and $\delta \mathrm{D}$ of molecular hydrogen in boreal forests: Ecosystem-scale systematics of atmospheric $\mathrm{H}_{2}$, Geophys. Res. Lett., 29(18), 1888, doi:10.1029/2002GL015118, 2002b.

Rahn, T., Eiler, J. M., Boering, K. A., Wennberg, P. O., McCarthy, M. C., Tyler, S. C., Schauffler, S., Donnelly, S., and Altas, E.: Extreme deuterium enrichment in stratospheric hydrogen and the global atmospheric budget of $\mathrm{H}_{2}$, Nature, 424, 918-921, 2003.

Rhee, T. S., Mak, J., Rockmann, T., and Brenninkmeijer, C. A. M.: Continuous-flow isotope analysis of the deuterium/hydrogen ratio in atmospheric hydrogen, Rapid Commun. Mass Spectrom., 18, 299-306, 2004.
Rhee, T. S., Brenninkmeijer, C. A. M., and Röckmann, T.: The overwhelming role of soils in the global atmospheric hydrogen cycle, Atmos. Chem. Phys., 6, 1611-1625, doi:10.5194/acp-61611-2006, 2006.

Rice, A., Quay, P., Stutsman, J., Gammon, R., Price, H., and Jaegle, L.: Meridional distribution of molecular hydrogen and its deuterium content in the atmosphere, J. Geophys. Res., 115, D12306, doi:10.1029/2009JD012529, 2010.

Sanderson, M. G., Collins, W. J., Derwent, R. G., and Johnson, C. E.: Simulation of global hydrogen levels using a lagrangian three-dimensional model, J. Atmos. Chem., 46, 15-28, 2003.

Schmitt, S., Hanselmann, A., Wollschlager, U., Hammer, S., and Levin, I.: Investigation of parameters controlling the soil sink of atmospheric molecular hydrogen, Tellus, 61, 416-423, doi:10.1111/j.1600-0889.2008.00402.x, 2009.

Schultz, M. G., Diehl, T., Brasseur, G. P., and Zittel, W.: Air pollution and climate-forcing impacts of a global hydrogen economy, Science, 302, 624-627, 2003.

Smith-Downey, N. V., Randerson, J. T., and Eiler, J. M.: Temperature and moisture dependence of soil $\mathrm{H}_{2}$ uptake measured in the laboratory, Geophys. Res. Lett., 33, L14813, doi:10.1029/2006g1026749, 2006.

Smith-Downey, N. V., Randerson, J. T., and Eiler, J. M.: Molecular hydrogen uptake by soils in forest, desert, and marsh ecosystems in california, J. Geophys. Res., 113, G03037, doi:10.1029/2008jg000701, 2008.

Snover, A. K. and Quay, P. D.: Hydrogen and carbon kinetic isotope effects during soil uptake of atmospheric methane, Global Biogeochem. Cy., 14, 25-39, 2000.

Talukdar, R. K., Gierczak, T., Goldfarb, L., Rudich, Y., Rao, B. S. M., and Ravishankara, A. R.: Kinetics of hydroxyl radical reactions with isotopically labeled hydrogen, J. Phys. Chem., 100, 3037-3043, 1996.

Tromp, T. K., Shia, R. L., Allen, M., Eiler, J. M., and Yung, Y. L.: Potential environmental impact of a hydrogen economy on the stratosphere, Science, 300, 1740-1742, 2003.

Warwick, N. J., Bekki, S., Nisbet, E. G., and Pyle, J. A.: Impact of a hydrogen economy on the stratosphere and troposphere studied in a 2-D model, Geophys. Res. Lett., 31, L05107, doi:10.1029/2003g1019224, 2004.

Xiao, X., Prinn, R. G., Simmonds, P. G., Steele, L. P., Novelli, P. C., Huang, J., Langenfelds, R. L., O’Doherty, S., Krummel, P. B., Fraser, P. J., Porter, L. W., Weiss, R. F., Salameh, P., and Wang, R. H. J.: Optimal estimation of the soil uptake rate of molecular hydrogen from the advanced global atmospheric gases experiment and other measurements, J. Geophys. Res., 112, D07303, doi:10.1029/2006jd007241, 2007.

Yonemura, S., Kawashima, S., and Tsuruta, H.: Continuous measurements of $\mathrm{CO}$ and $\mathrm{H}_{2}$ deposition velocities onto an andisol: Uptake control by soil moisture, Tellus, 51, 688-700, 1999.

Yonemura, S., Kawashima, S., and Tsuruta, H.: Carbon monoxide, hydrogen, and methane uptake by soils in a temperate arable field and a forest, J. Geophys. Res., 105, 14347-14362, 2000. 